\title{
PENERAPAN HYPNOPRENATAL PADA IBU HAMIL DI POSYANDU ANYELIR WILAYAH KERJA PUSKESMAS DEMPO PALEMBANG
}

\author{
Elita Vasra ${ }^{1}$, Nurul Komariah ${ }^{2^{*}}$, Kharisma Virgian $^{3}$ \\ ${ }^{1-3}$ Poltekkes Kemenkes Palembang \\ Email: nurulkomariah2007@gmail.com
} DOI: https://doi.org/10.33024/jkpm.v5i2.4741

Diterbitkan: 04 Februari 2022

\section{ABSTRAK}

Kehamilan merupakan hal yang sangat membahagiakan bagi seorang wanita. Dalam melewati kehamilannya seorang ibu hamil merasa tidak percaya diri, merasa tidak nyaman dengan kehamilannya serta merasa tidak tenang dan khawatir terutama akan persalinannya. Hypnoprenatal merupakan salah-satu metode hypnosis yang dilakukan pada ibu hamil. Hypnoprenatal merupakan upaya untuk menyakinkan ibu hamil bahwa dia bisa menjalani kehamilannya. Sasaran dari kegiatan pengabmas ini adalah ibu hamil. Tujuan kegiatan ini yaitu pemberdayaan ibu hamil melalui hypnoprenatal. Dilakukan tiga tahapan kegiatan yaitu wawancara pendahuluan, pelaksanaan hypnoprenatal dan evaluasi. Jumlah ibu hamil 10 orang dengan usia antara 18 tahun - 30 tahun, jenjang pendidikan yaitu SMP-SMA. Dilakukan hypnoprenatal pada ibu hamil diberikan sugesti dan kata-kata positif diringi dengan irama dan terapi musik relaksasi yang menenangkan dan menambah kepercayaan diri yang tinggi bagi ibu hamil. Setelah diberikan Hypnoprenatal terdapat perubahan yang lebih baik pada ibu hamil. Pada awal wawancara sebelum kegiatan dilakukan terdapat ibu-ibu yang mengeluh cemas dengan kehamilannya. Namun setelah dilakukan hypnoprenatal ibu merasa tampak lebih tenang dan merasa yakin dan percaya diri dalam menjalani kehamilannya.

Kata Kunci: Hypnoprenatal, Ibu Hamil, Relaksasi

\begin{abstract}
Pregnancy is a very happy thing for a woman. In going through her pregnancy, a pregnant woman feels insecure, feels uncomfortable with her pregnancy and feels uneasy and worried, especially about her delivery. Hypnoprenatal is one of the methods of hypnosis performed on pregnant women. Hypnoprenatal is an attempt to convince pregnant women that she can live her pregnancy. The target of this community service activity is pregnant women. The purpose of this activity was to empower pregnant women through hypnoprenatal. Three stages of activities were carried out, namely preliminary interviews, hypnoprenatal implementation and evaluation. The number of pregnant women were 10 people with ages between 18 and 30 years, the education level is SMP-SMA. Hypnoprenatal was performed on pregnant women given positive suggestions and words accompanied by rhythms and relaxation music therapy that soothes and
\end{abstract}


adds high self-confidence for pregnant women. After being given Hypnoprenatal there is a better change in pregnant women. At the beginning of the interview before the activity was carried out there were mothers who complained of anxiety about their pregnancy. However, after hypnoprenatal, the mother felt calmer and felt confident and confident in her pregnancy.

Keywords: Hypnoprenatal, Pregnant Women, Relaxation

\section{PENDAHULUAN}

Setiap wanita menginginkan persalinan berjalan lancar dan dapat melahirkan bayi secara sempurna.Persalinan merupakan moment yang sangat membahagiakan yang tidak perlu ditakuti oleh seorang wanita, tetapi masih banyak perempuan yang merasa khawatir, cemas dan gelisah menanti saat kelahiran tiba. Secara tiori disampaikan bahwa 90-95\% persalinan seharusnya dapat berjalan normal pervaginam tanpa komplikasi. (Philip, 2015).

Faktanya, masih banyak persalinan yang berakhir dengan induksi dan seksio Caesaria (SC) Di Indonesia berdasarkan hasil Riset Kesehatan Dasar (Riskesdas) 2018 menunjukkan prevalensi tindakan sesar pada persalinan adalah 17,6 persen, tertinggi di wilayah DKI Jakarta $(31,3 \%)$ dan terendah di Papua (6,7\%). His atau kontraksi mutlak dibutuhkan untuk terjadinya pembukaan serviks saat proses persalinan maupun untuk pengeluaran bayi. (Maria, 2012), (Prawirohardjo, 2014)

Secara fisiologis, kontraksi akan menyebabkan rasa nyeri karena adanya penekanan pada syarat di daerah ganglion servikal. (Leeman L, 2003) akan memicu terjadinya kecemasan pada ibu bersalin, tercatat sebesar $55 \%$ ibu bersalin mengalami kecemasan. His bisa terjadi dengan baik jika hormon oksitosin dalam tubuh mencukupi. Hormon ini akan diproduksi dengan baik jika seorang wanita merasa rileks dan tidak dalam keadaan cemas. (Leeman L, 2003)

Kecemasan yang dialami wanita akan meningkatkan produksi hormon serotonin. Hormon Serrotonin dapat menghambat kerja oksitosin. Akibatnya seorang ibu bersalin yang seharusnya bisa bersalin secara normal harus dilakukan intervensi medis induksi persalinan dengan oksitosin drip yang menyebabkan rasa nyeri bertambah hebat.(Leeman L, 2003) (Non A, 2004). Kecemasan serta rasa nyeri dapat dikurangi dengan meningkatkan kemampuan ibu untuk relaksasi selama kehamilan dan persalinan serta melakukan persiapan fisik dan psikologis (Imaniar,2020).

Penelitian oleh Tridamayanti 2012 (Kusbandiyah,2014) pada salah satu bidan praktek di Malang, dari 10 persalinan, terdapat 7 persalinan yang dilakukan episiotomi. Banyak hal yang menyebabkan dibutuhkannya episiotomi saat persalinan salah satunya adalah kelenturan vagina yang sebenarnya bisa dilatih sejak hamil. Posisi persalinan yang lazim digunakan juga tidak bervariasi hanya lithothomi dan dorsal recumben. Padahal posisi persalinan bisa sangat beragam untuk meminimalisir terjadinya robekan jalan lahir.

Penelitian oleh Jiarti tahun 2013 (Kusbandiyah, 2014) mendapatkan hasil bahwa, dengan dilakukan hypno selama kehamilan, ibu hamil merasa lebih tenang dan kecemasan menjadi berkurang. Dengan relaksasi akan mendapatkan hasil yang lebih maksimal. Penelitian Vasra (2018), yang hasilnya menunjukkan bahwa perlunya dukungan yang kuat antara petugas 
dan keluarga untuk mengelola ketidaknyamanan yang dialami ibu saat trimester III dan proses persalinan. Salah-satu cara mengelola ketidaknyamanan tersebut yaitu dengan hypnoprenatal.

Kelas hypnoprenatal merupakan sesi hypnoterapy bagi ibu hamil yang dapat dilakukan secara individu atau berkelompok dengan jumlah maksimal 10 ibu hamil. Usia kehamilan 20 minggu, dengan jarak pertemuan minimal 1 minggu dan maksimal 3 minggu (Susilowati,2017). Tujuan kegiatan Pengabmas ini adalah Pemberdayaan ibu hamil melalui penerapan hypnoprenatal di Posyandu Anyelir Puskesmas Dempo Palembang Tahun 2019.

\section{MASALAH}

Alasan kami memilih tempat kegiatan karena di Posyandu Anyelir terdapat ibu hamil yang cemas dengan kehamiannya.

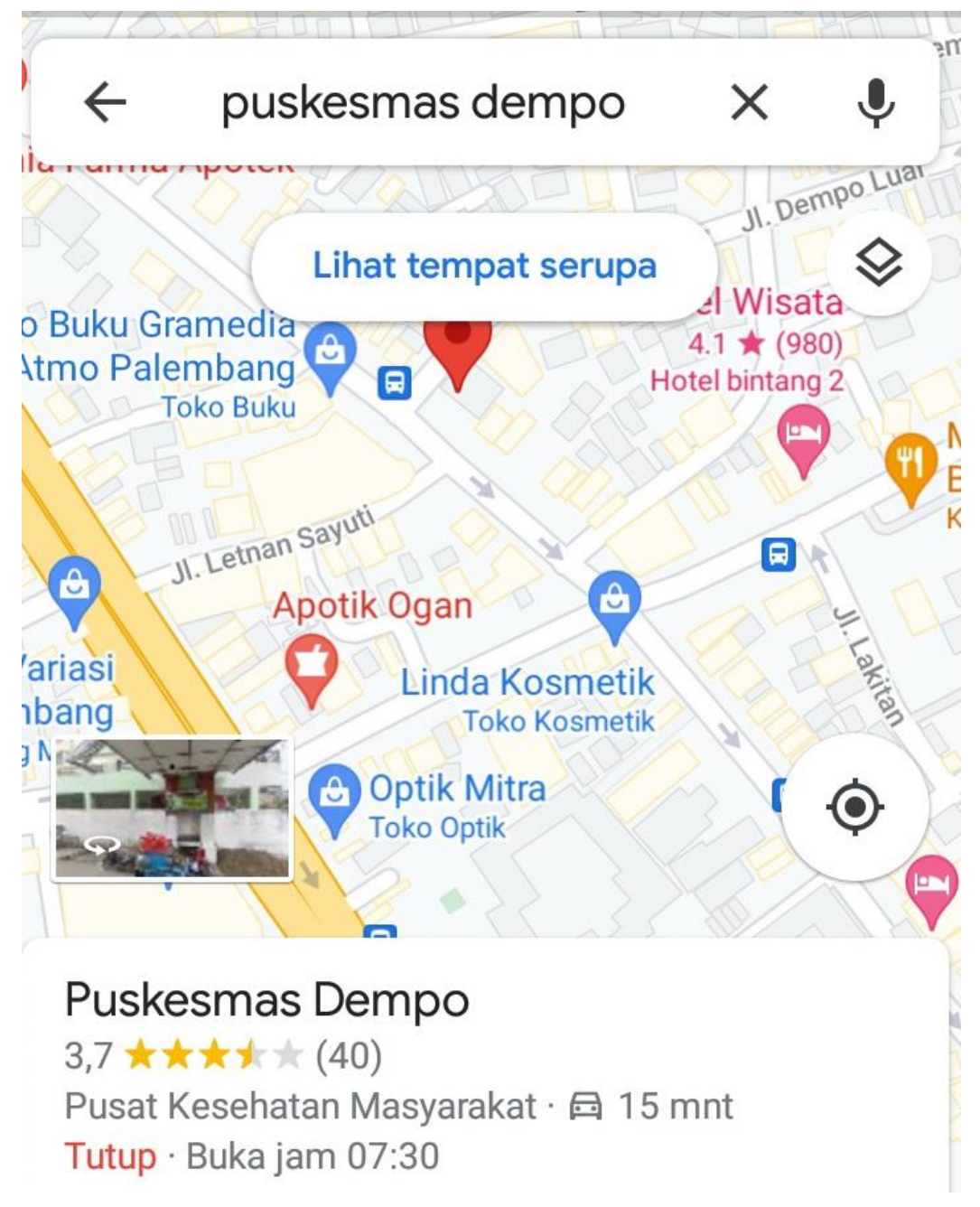

Gambar 1. Peta Lokasi Kegiatan Pengbdian Kepada Masyarakat. 


\section{METODE}

\section{a. Jumlah Responden}

Populasi: Ibu hamil yang berada di Posyandu Anyelir wilayah kerja Puskesmas Dempo Palembang. Sampel: Semua ibu hamil yang berada di Posyandu Anyelir Puskesmas Dempo Palembang yang memenuhi kriteria inklusi dan eksklusi.

Kriteria Inklusi:

1). Pasien yang bersedia menjadi responden

2). Pasien hamil TM III

Kriteria Eksklusi:

Pasien memiliki komplikasi kehamilan.

Penarikan sampel dengan menggunakan accidental sampling.

Waktu Pelaksanaan:9 Oktober 2019.

Lokasi: Posyandu Anyelir Puskesmas Dempo Palembang.

b. Metode dan Proses jalannya Pengabdian

1) Melakukan pengurusan surat izin kegiatan pada Kesbangpolinmas dan Puskesmas.

2) Melakukan pendataan ibu hamil yang berada di wilayah Posyandu Anyelir Puskesmas Dempo Palembang.

3) Bekerja sama dengan kader dalam pendataan dan peningkatan jumlah participation rate responden.

4) Sebelum pelaksanaan kegiatan dilakukan wawancara terlebih dahulu berkaitan dengan perasaan dan keluhan ibu selama hamil ini.

5) Kemudian dilakukan hypnoprenatal

6) Setelah Hypnoprenatal dilakukan kembali wawancara terkait dengan perasaan ibu setelah hypnoprenatal.

\section{HASIL DAN PEMBAHASAN}

Kegiatan Pengabdian kepada Masyarakat bertujuan untuk mengembangkan ilmu pengetahuan dan teknologi di bidang kebidanan sehingga masyarakat dapat menikmati hasilnya. Agar kegiatan kepada masyaakat ini dapat diketahui dan dirasakan manfaatnya oleh masyarakat.

Kegiatan Pengabmas ini adalah berupa pemberdayaan ibu hamil melalui hypnoprenatal di Posyandu Anyelir Puskesmas Dempo Kota Palembang Tahun 2019. Peserta terdiri atas 10 orang ibu hamil. Pada tahap pertama dilakukan wawancara terlebih dahulu pada setiap ibu hamil untuk memperoleh biodata serta apa keluhan ibu selama hamil dan perasaan ibu selama hamil, harapan dan ketidaknyamanan ibu selama hamil. Ibu hamil sebagian besar cemas dengan kehamilannya dan khawatir dalam menghadapi persalinannya. Selanjutnya, diberikan hypnoprenatal dengan memberikan kalimat-kalimat dan sugesti positif pada ibu hamil agar mempunyai keyakinan dan kepercayaan diri yang tinggi pada saat hamil serta irama relaksasi agar ibu merasa tenang, rileks dan nyaman. Pada tahap ketiga dilakukan evaluasi dengan menanyakan kepada ibu bagaimana perasaannya setelah dilakuka hypnoprenatal. Rata-rata ibu merasa lebih tenang, nyaman, dalam menjalani kehamilannya. Serta kembali menilai kecemasan ibu hamil kembali dengan menggunakan kuesioner.

Dari kegiatan penerapan hypnoprenatal ini dapat dilihat bahwa terdapat perubahan yang lebih baik sebelum dan sesudah dilakukan hypnoprenatal pada ibu hamil. Pada awal wawancara sebelum kegiatan dilakukan terdapat 
ibu-ibu yang mengeluh cemas dengan kehamilannya. Namun setelah dilakukan hypnoprenatal ibu merasa tampak lebih tenang dan merasa yakin dan percaya diri dalam menjalani kehamilannya.

Kegiatan ini dapat dilakukan pada saat pelaksanaan kelas ibu hamil setiap bulannya dan ibu dapat melakukan sendiri di rumah. Demikian juga saat dilakukan kunjungan rumah (home visit) ke salah-satu ibu hamil, ibu menyatakan sekarang dia lebih nyaman dan tenang dalam menjalani kehamilannya.

Hasil kegiatan ini sejalan dengan penelitian sebelumnya. Penelitian Nursanti (2017) menunjukkan bahwa hypnoprenatal efektif untuk mengatasi kecemasan ibu hamil dalam menghadapi proses persalinan sehingga membuat proses persalinan lebih lancar, aman, dan nyaman. Demikian juga dengan penelitian Suryaningsih (2019) menunjukkan bahwa ibu dapat mengatasi kecemasan dan merasa lebih tenang dalam menjalani kehamilannya dan merasa lebih siap dalam menghadapi persalinan.
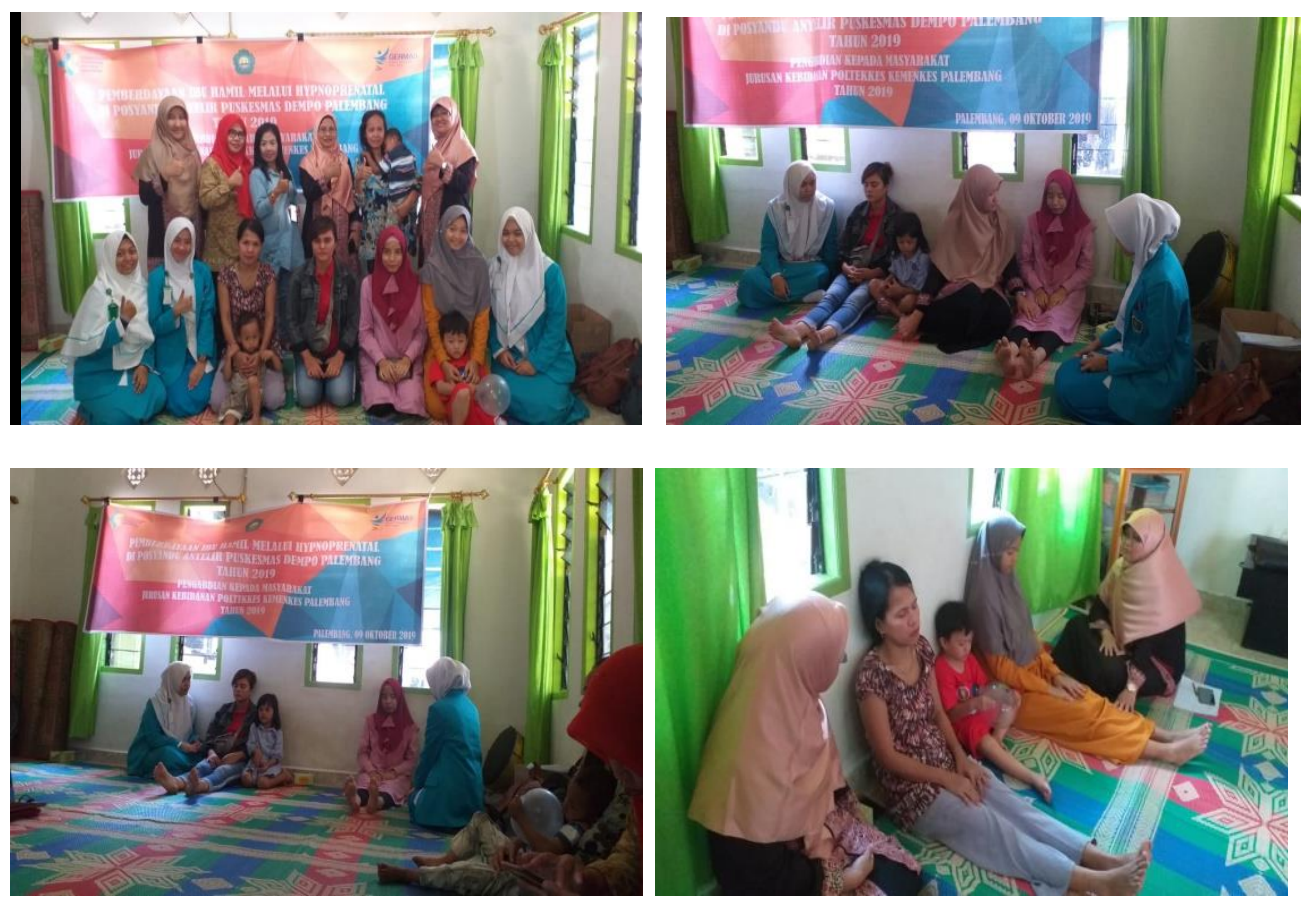

Gambar 2. Kegiatan PKM

\section{KESIMPULAN}

Kegiatan pengabmas pemberdayaan ibu hamil di Posyandu anyelir dapat meningkatkan kepercayaan diri ibu dalam menjalani kehamilannya. Kegiatan pengabmas pemberdayaan ibu hamil membuat ibu lebih rileks dan nyaman serta lebih tenang dalam menjalani kehamilannya. Adapun saran yang dapat diberikan yaitu: Kepada Pihak Puskesmas dan Posyandu agar dapat lebih meningkatkan pelayanan yang berkaitan dengan psikologis ibu hamil. Kegiatan hypnoprenatal dapat menjadi salah-satu kegiatan kelas ibu hamil sehingga dapat meningkatkan kepercayaan diri ibu hamil serta membuat ibu lebih nyaman dan tenang dalam menjalani kehamilannya. 


\section{DAFTAR PUSTAKA}

Imaniar, MS. Sundari,SW. Windiyani,W. (2020). Gentle Birth Untuk Kenyamanan Persalinan Di Kelas Ibu Hamil Puskesmas Bungursari Tasikmalaya. Jurnal Abdimas PHB 3 (2):10-15. DOI: http://dx.doi.org/10.30591/japhb.v3i2.1826

Kementerian Kesehatan Republik Indonesia. (2018). Laporan Nasional Riset Kesehatan Dasar 2018 (Report of Indonesian Basic Health Survey 2018). Jakarta, Indonesia: Kementerian Kesehatan RI.

Kusbandiyah, J. Dwi, Jl.(2014). Peran Hypnobirth Dan Gentle Birth Saat Prenatal Class Untuk Kenyamanan Dan Kelancaran Proses Persalinan. Jurnal Ilmiah Kesehatan Media Husada 03(01).21-30 DOI: https: / / doi.org/10.33475/jikmh.v3i1.132

Leeman, L. Fontaine,P. King,V, et al. (2003). The Nature And Management Of Labor Pain: part I: Non Pharmacologic Pain Relief. Am Fam Physician. 68(6):11091112. https: / /www.aafp.org/afp/2003/0915/afp20030915p1109.pdf

Leeman, L. Fontaine, P. King, V. et al. (2003). The Nature And Management Of Labour Pain :part II. Pharmacologic pain relief. Am Fam Physician. 68(6):11159-1120. https: / /www.aafp.org/afp/2003/0915/afp20030915p1115.pdf

Maria, A. Wijayarini. (2012). Buku ajar Keperawatan Maternitas edisi 4: Jakarta, Indonesia:EGC.

Non A. (2004). Pain In The Elderly. In: Warfield CA. Principles And Practice Of Pain Management. New York, USA: Mc Graw Hill.

Nursanti, R. (2017). Efektivitas Hypnoprenatal Class Terhadap Kecemasan Ibu Hamil Dalam Menghadapi Proses Persalinan. JPP jurnal kesehatan Poltekkes Palembang. 12 (2): 20-24.

Phillips-moore, J S. (2015). Birthing Outcomes From An Australian HypnoBirthing Programme. British Journal of Midwifery. 20(8): 558-564. doi: 10.12968/bjom.2012.20.8.558.

Prawirohardjo, Sarwono. (2014). Ilmu Kebidanan Sarwono Prawirohardjo. Jakarta, Indonesia: PT. Bina Pustaka Sarwono Prawirohardjo

Susilowati, U.(2017). Hypnosis Dalam Kebidanan.Surakarta, Indonesia: IBH.

Suryaningsih, S. Rodiyatun, R. M.Choirin, MC. Kusumaningtyas, K. (2019). Peningkatan Empowerment (Pemberdayaan) Perempuan Melalui Kelas Hypnoprenatal Pada Ibu Hamil. Jurnal Unusa; 3 (1): 18-26. https://doi.org/10.33086/cdj.v3i1.1100

Vasra, E. Murdiningsih. (2018). Pengaruh Antenatal Class Terintegrasi Gentle Birth Dan Hypnoprenatal Terhadap Proses Kelahiran Pada Kelas Ibu Hamil Di Puskesmas Pembina Dan BPM Husniyati Palembang. Palembang, Indonesia: Poltekkes Kemenkes Palembang. 